\title{
Conceptual Design and Fashion's Futures in the Afropolis
}

\author{
Kerstin Pinther
}

\section{1 Introduction}

Research into fashion and sartorial styles was and still is not a core subject of African studies. ${ }^{1}$ Fashion's reputation as superficial and anti-fashion discourses have also likely left their mark on African studies. Even the earliest sociological theories addressed fashion in purely critical terms. Barbara Vinken has repeatedly pointed out how fashion has been stigmatized in Western thinking as effeminate and idolatrous. "To denounce fashion is part of a dark heritage of modernity", she writes (Vinken 2019: 61). Only recently has fashion been taken more seriously within academia and acknowledged as an essential part of contemporary culture and public life. ${ }^{2}$ In addition, there is some evidence that among many intellectuals and artists in Africa this negative attitude towards fashion and its alleged superficiality is not shared. One need only refer to the Senegalese filmmaker Sembène Ousmane, whose films like Xala (1974) express a pronounced sensitivity to the language and meaning of fashion and dress. And, Lesley Lokko, a UK trained, Scottish-Ghanaian architect and writer, is generally critical of the pervasive conception of surface

1 Important exceptions here are the art historical and anthropological studies of textiles or clothing practices, particularly their political significance as markers of identity (Allmann 2004; Eicher 1995; Eicher and Ross 2010). Within the last decade, however, empirical research on fashion design in Africa and its diaspora (Mustafa 1998; Richards 2016; Rovine 2015; Tulloch 2016) provided an important corrective and complemented hitherto mainly Westcentric fashion studies. These produce research on Africa's expressive cultures and speak to the changed cartography of fashion and question the dominance of Western fashion centres (Breward and Gilbert 2006; Potvin 2009) in favour of a more polycentric fashion industry.

2 It is in the context of rising research on fashion and, in particular, its relationship to the city and Afropolis, that the DFG project Fashion and Styles in African Cities is located. The collaborative project is led by Basile Ndjio (University of Douala), Kerstin Pinther (Ludwig Maximilian University of Munich) and Frank Ugiomoh (University of Port Harcourt); it empirically explores the interrelationships between fashion and the city using the examples of Dakar, Douala and Lagos and combining art history and anthropological perspectives. Thus, this text draws on participant observation, informal conversations and interviews with designers and artists in the fashion field. I thank my colleagues and the reviewers for their valuable comments. For publications connected to the project, see Kastner (2019), Oberhofer (2012) and Pinther et al. (2022).

(C) KERSTIN PINTHER, 2022 | DOI:10.1163/9789004471641_021

This is an open access chapter distributed under the terms of the CC BY-NC 4.0 License. 
as lacking importance and being insubstantial - an antipathy towards colour included. ${ }^{3}$ Instead, she introduces the concept of the thick skin, arguing that the surface is profound and essential; the appearance then plays a crucial role in the making of a person (Lokko 2018: 131-2). The following examples bear witness to the concept of the body and fashionable clothing as a repository of knowledge, identity and self-expression. It is the aim of my contribution to analyse fashion as a collaborative process between designers, artists and photographers, using the example of the vibrant fashion scenes in Lagos, Nigeria. I will show that craft and manual work play a vital role in shaping textile and design futures in Africa. In addition, I will demonstrate how designers not only research textile and sartorial practices, but also unpack hidden or forgotten societal beliefs and institutions.

Amaka Osakwe is certainly one of the most famous contemporary fashion designers from Nigeria. In 2010 she founded her label Maki Oh in Lagos, the cultural metropolis of the country and one of Africa's fastest-growing globally connected fashion cities. Since then, Amaka Osakwe has not deviated from her standard of producing exclusively in Nigeria and, above all, using locally sourced materials and textile techniques. Unlike some other Nigerian fashion designers - Lisa Folawiyo being at the forefront of those using and adapting Ankara (wax prints) into a heavy texture - Amaka Osakwe vehemently rejects Dutch Wax as a signifier of 'Africanness'. Instead, she believes in the valorization and exploration of locally available textiles and creates her designs around the resist-dyed Indigo adire and the narrow woven strips of aso oke. Characterized by a mix of disparate materials and fabrics such as handmade textiles, the fibrous strands of a loofah sponge, paired with chiffon and tulle, also lace and leather, jersey and silk, her garments often reveal the layered and draped appearance of 'traditional' sartorial practices. Some pieces in the autumn/winter 2016 season oscillate between clear cuts and more playful elements such as flounces, frills and other embellishments to evoke the body-accentuating silhouettes of the 'classical' Nigerian womenswear with voluminous blouses and wrappers. Printed and appliquéd eyes are recurrent motifs in this collection and, according to Amaka Osakwe, are reminiscent of the well-known adire motif of the 'inner eye', alluding to self-reflection on one side, and being seen and observed on the other side. Her autumn 2017 line of clothing again was inspired by the aesthetics of the bright yellow Danfo minibuses that criss-cross Lagos and that are covered with slogans and stickers - the latter translated into

3 In his important essay "Style and Ontology", Daniel Miller (1994) also argues for the relevance of the surface within Trinidadian fashion and style practices. 
various forms of painted adire and embroidery, wildly ornate and with unsewn threads.

The collection's underlying narration is that of a middle-class woman who travels through Lagos at night to see her lover - each single outfit speaks to local dressing habits and strategies. ${ }^{4}$ As Victoria Rovine (2015:3) remarked for some of Osakwe's early designs, these more recent collections also evoke place and culture through "two layers of sartorial references, one literal and one conceptual". Her designs are not only anchored locally through their materialities, colours and shapes, but also through subtle thematic references, taken up in the accompanying visuals, for which she often cooperates with artist friends like the architect and filmmaker Papa Omotayo. ${ }^{5}$ Most of his fashion videos for Amaka Osakwe/Maki Oh transfer the ideas and stories behind the designs into an atmospherically dense and nuanced narration of Lagos and its specific urban milieux - visually and acoustically. Omi - Water for example, a film that won the Milano Fashion Film Festival award in 2016, evolved around the urban myth of Mami Wata. Omotayo placed a slide projector's switch into the hand of the female model as if to underline that she is the one who is controlling her image. With unfinished houses and other non-permanent sites being used as settings, the visual further suggests identities in the making. Another video plays with the variations of the word 'ehn', commonly heard in Lagos streets. Depending on context and intonation, it carries different meanings, from 'yes', to 'I guess' and 'is this how it's going to be?' As these visuals and designs are often associative, they are used to tell provocative and complex stories about female self-images, desire, sexual freedom and socio-cultural expectations of black womanhood. ${ }^{6}$

Amaka Osakwe is part (or even forerunner) of a growing group of fashion designers in and beyond Nigeria who understand fashion design practice as an active form of social commentary and critique. What in the past (at least in the Western context) was very much bound to subcultural styles has now been absorbed into the fashion industry itself, meaning that critical fashion from Alexander McQueen to Rei Kawakubo and Hussein Chalayan ${ }^{7}$ - aims to

4 See her homepage: https://www.instagram.com/p/BQsivkRgbG-/ [7 November 2020].

5 The architect Papa Omotayou is the founder of the Lagos-based Whitespace Creative Agency. I met him there for an interview in October 2018. Some of his fashion clips can be watched on YouTube https://www.youtube.com/watch?v=uMPQb6hG5UI [5 November 2020].

6 Because of its differentiated approach, a text by Alexis Okeowo (2017) on Amaka Osakwe, entitled "West Africa's most daring designer", for The New Yorker was particularly well received and discussed among designers and artists.

7 In this context, Chalayan's autumn/winter collection 2000 entitled Afterwords is a much cited example of a design for debate insofar as this Turkish-Cypriot fashion designer living in 


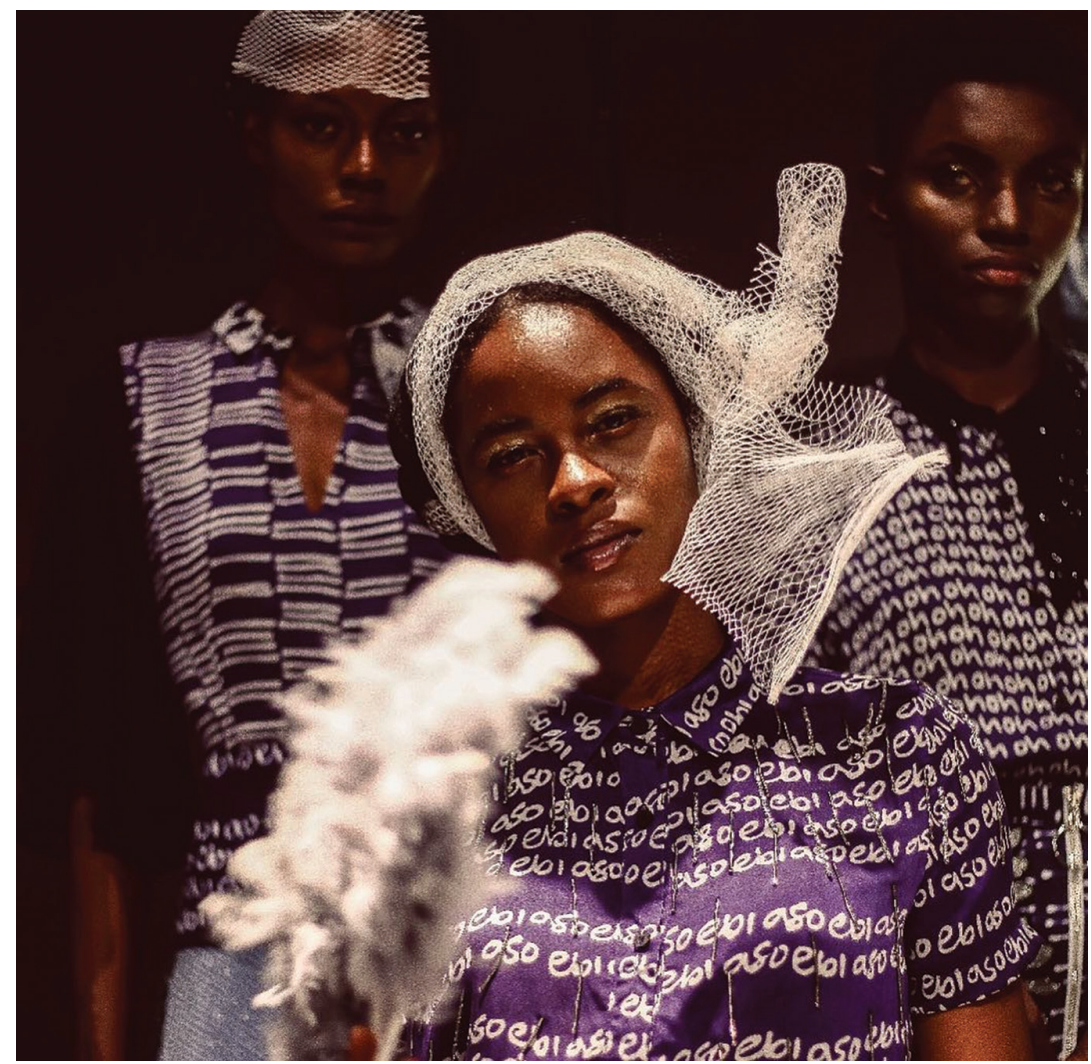

FIGURE 1 Maki Oh, designed by Amaka Osakwe. Summer collection 2017, presented at Alara, Lagos PHOTO: MANNY JEFFERSON. INSTAGRAM ACCOUNT OF MAKI OH, HTTPS://WWW.INSTAGRAM.COM/P/BN2YBZGHP8-/

disrupt societal conventions or to comment on political or social challenges (Geczy and Karaminas 2017).

Because there are so few (fashion) design educational institutions in Africa, several of today's designers from various places in Africa were trained in Europe or North America. Their aesthetic and stylistic references, as well as their

London was one of the first to tackle issues of migration and forced displacement by transforming furniture into mobile garments. In the Nigerian context Buki Agbabiaka (alias Buki Akib) marked her return from London, where she graduated from the Central Saint Martins College of Arts and Design, with her Homecoming Collection in 2012. The chosen topic of travel, movement and return - a well-known topos in African literature and postcolonial thinking - was translated into fashion mainly by accessories and the accompanying lookbook with images taken by Lakin Ogunbanwo at the Nigerian Railway Corporation in Ebute Metta, Lagos (see Pinther 2013). 


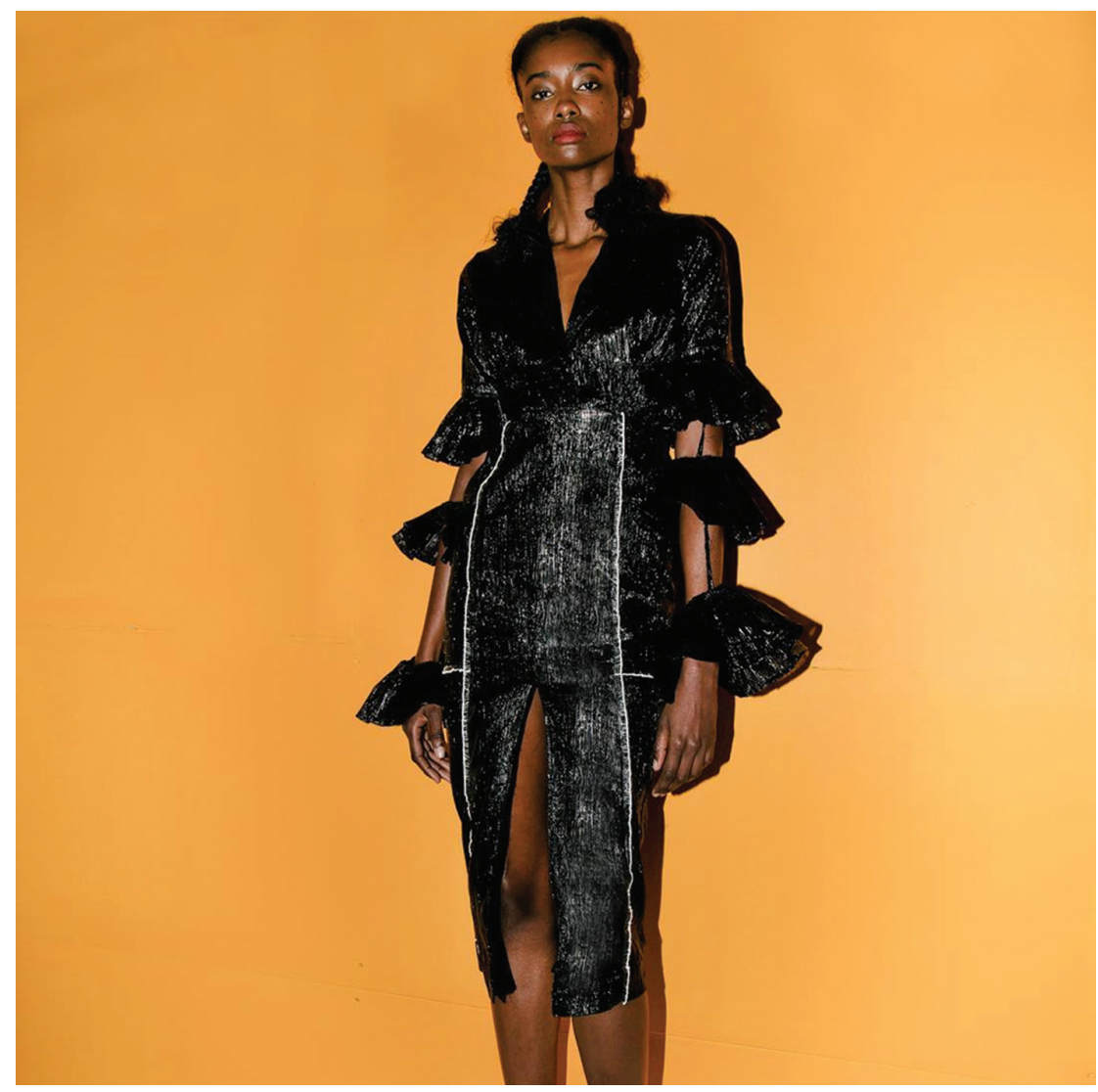

FIGURE 2 Maki Oh, designed by Amaka Osakwe. Fall 2017, No Dulling, Look 3 INSTAGram ACCOUNT OF MAKI OH, HTTPS://WWW.INSTAGRAM.COM/P/BQSIVKRGBG-/

networks, are wide-ranging; fashion made in Nigeria is directed to both a local, predominantly urban clientele, and to the global fashion world, the black diaspora explicitly included. Amaka Osakwe was trained in England, returned to Lagos and now contributes to its fame as an important fashion city on the African continent. Moreover, she aims to redevelop the local fashion industry, which often means working with craftspeople and different trades. Her practices, and those of other designers, can be characterized by both a local rootedness and a global connectedness pursuing a conceptual approach to fashion. With many other designers of the continent, she shares a strong interest in local textile techniques and craft activities. Making and handmade practices in design gain new and even greater importance as they undergo updates through new forms that the digital and material experiences provide. It is this critical impulse in many fashion designers' approaches that is directed towards possible futures. 
In 2007, at the age of 20, Papa Oyeyemi founded the menswear label Maxivive as an autodidact. Since then he has been producing from his studio in Yaba, a popular and mixed neighbourhood on the Lagos mainland. He is wellknown for his gender-fluid approach and his Harmattan 2019 collection 'How to Marry a Billionaire' is probably most explicit about non-hetero-normative gender identities. Among the looks presented at the Lagos Fashion Week were many slogan sweaters and trousers with statements in bold glittering letters such as 'Bad Bitch No Underwear' or the ambiguous 'Buysexual'-shirt with sleeves ending in 'fingers'. Male models were dressed in tight, light pink or pale red velvet trousers and semi-transparent lace outfits; they wore wide skirts in bright colours, woolly jackets with side zips and yellow plastic gloves. Lurex as a continuation of the glittering theme of past collections was paired with more mundane, and rarely used in contemporary fashion design in Nigeria, materials such as PVC, bought at local markets. Some pieces, as Papa Oyeyemi said in an interview, ${ }^{8}$ were inspired by the idiosyncratic way of dressing he recognized among the sellers in a nearby market. Thus, some of his designs showcased the everyday context of African cities as sites of intrinsic, but undocumented aesthetic values. For others - such as the green boysgirls-top - he made use of second-hand cloth which was modified after purchase. The collection comes as a journey through elaborately embroidered fabrics, optical illusions that revolve

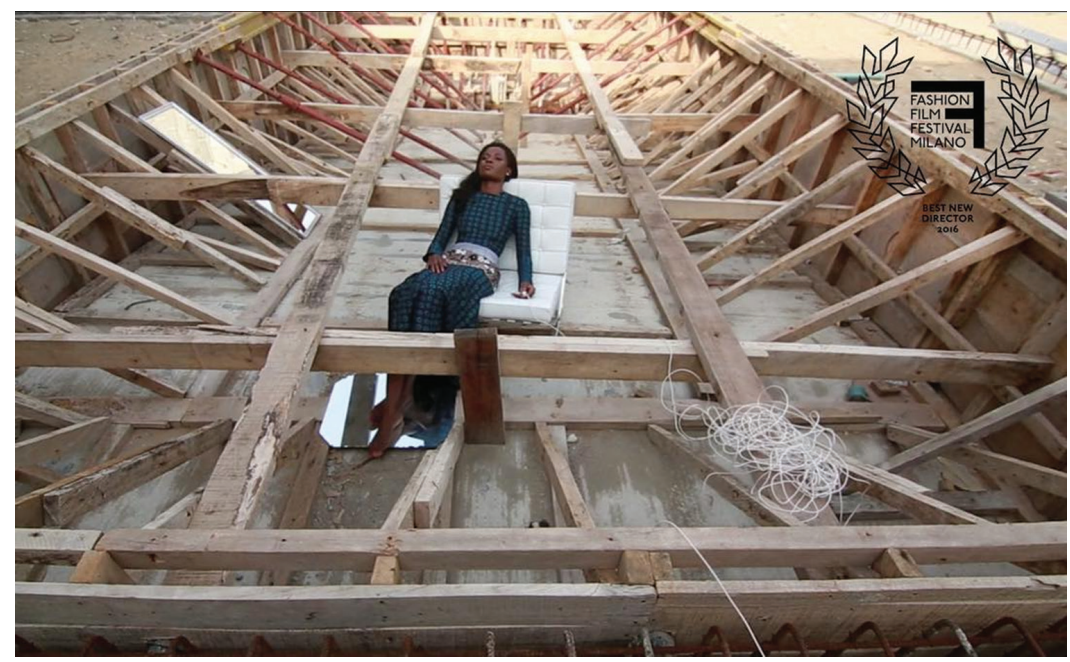

Figure 3 Papa Omotayo (A whitespace) and Amaka Osakwe for Maki Oh, 'Omi' at the fashion film festival milano INSTAGRAM ACCOUNT OF MAKI OH, HTTPS://WWW.INSTAGRAM.COM/P/BLLTTI_HSDT/

8 The interview took place in Yaba, October 2018. 


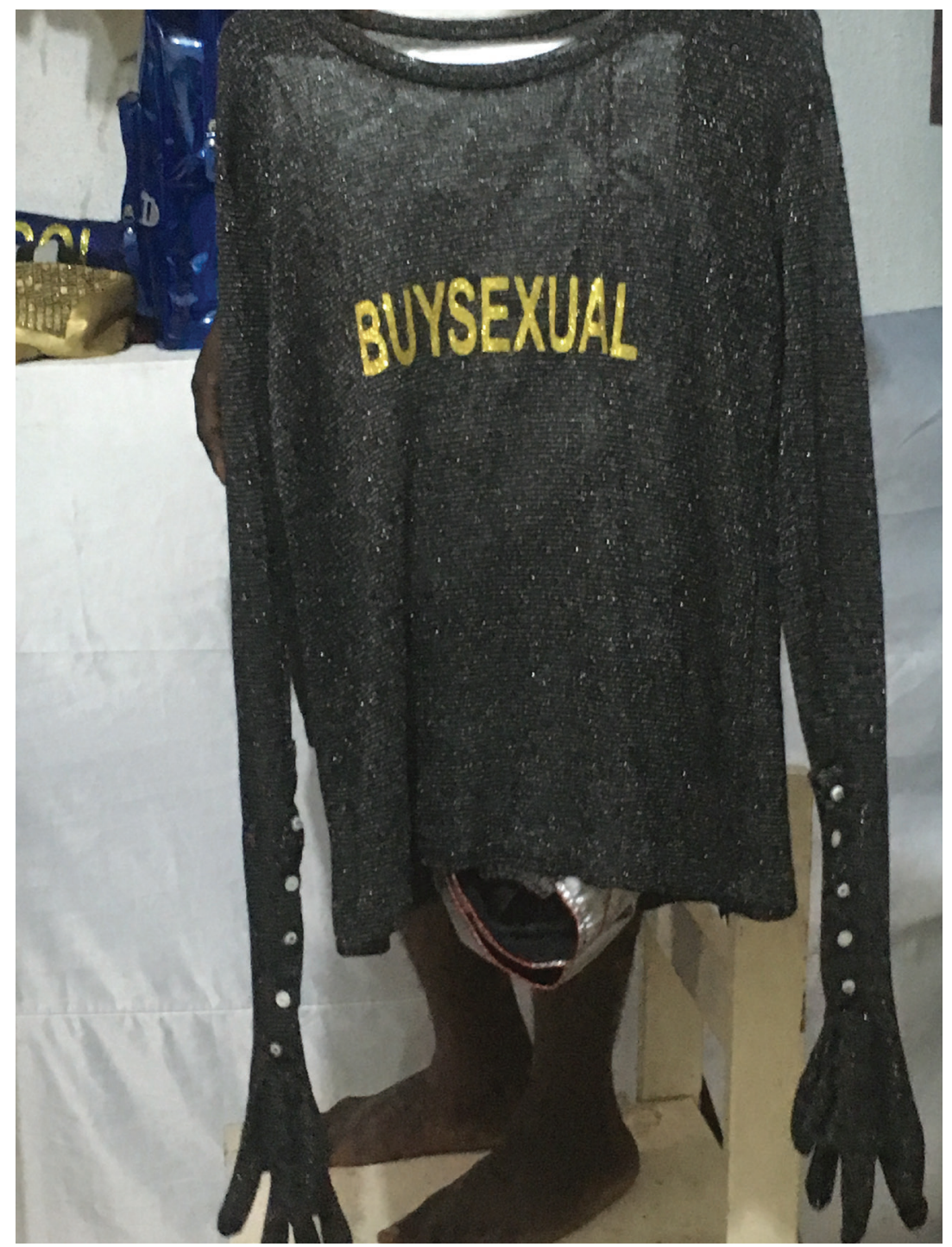

FIGURE 4 Maxivive designed by Papa Oyeyemi: 'Buysexual'-shirt with sleeves ending in 'fingers' PHOTO: KERSTIN PINTHER

around themes such as self-determination, relationships of dependence and supposed wealth. In the middle of the show, the models started appearing in bridal veils over their outfits. In a reversal of the common cliché that the very last model wearing the very last look is a bride, Papa Oyeyemi sent the whole group of models onto the stage - all with pastel bridal veils of tulle as if to celebrate a collective wedding ceremony. 


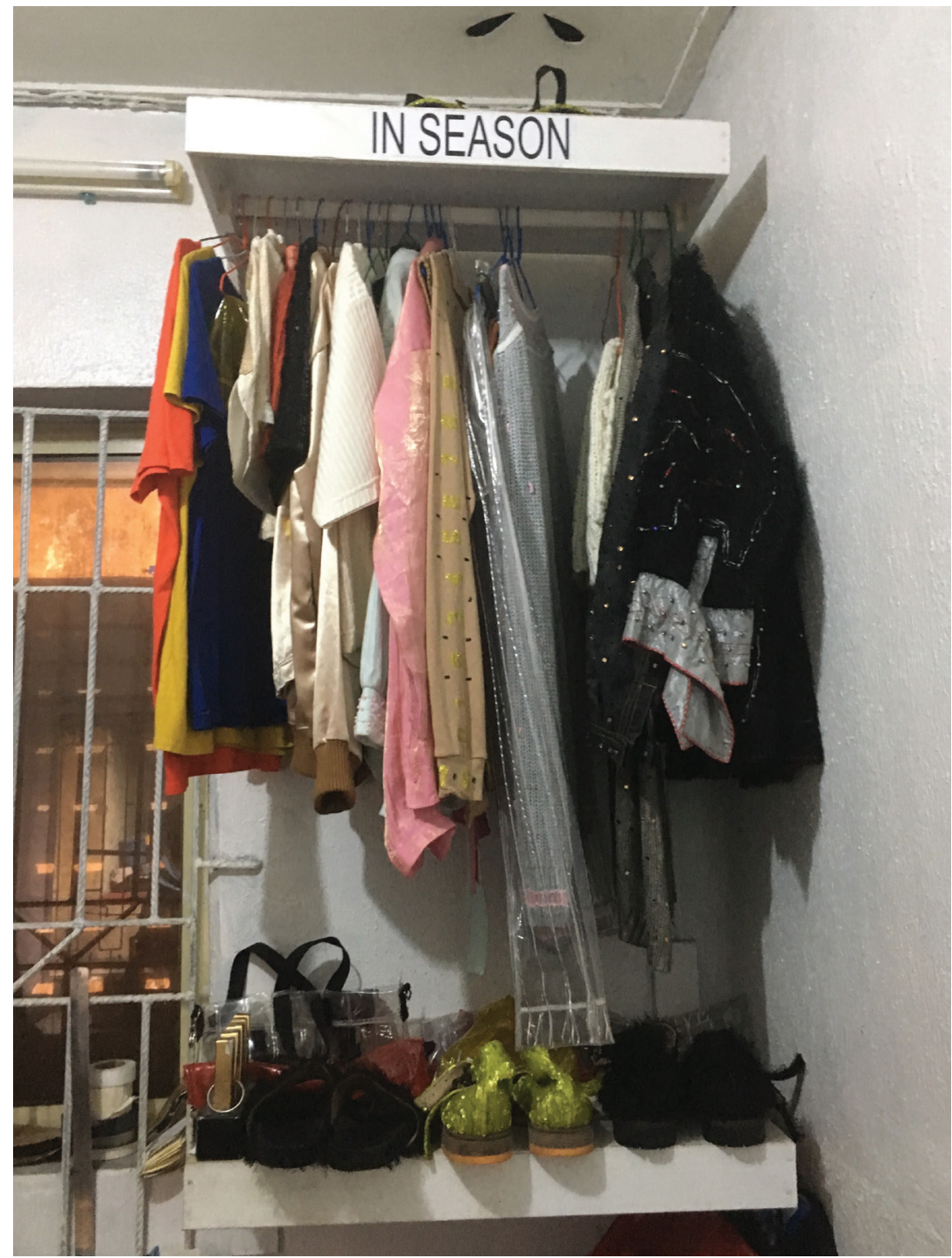

FIGURE 5 The glittering aesthetic in the studio of Papa Oyeyemi / Maxivive in Yaba, Lagos PHOTO: KERSTIN PINTHER

The designer, who not only refuses to accept the Western fashion calendar, but also introduced more appropriate seasons for the Nigerian context such as Harmattan, the wet and dry season, stands for a provocative yet highly nuanced conversation on non-conformity in fashion and society. And - as one has to keep in mind - this happens against the juridical background of 
homosexuality in Nigeria, which has been punishable by law since 2014 when the former President Goodluck Jonathan passed the Same-Sex Marriage (Prohibition) Bill. Maxivive uses and plays with material considered inappropriate in more mainstream fashion or not in accordance with conventional concepts of male beauty. In terms of fabric, pattern cutting and construction, his designs often contradict sartorial norms in Nigeria, as they tend to follow the religious conventions of a predominantly heteronormative society. And so the reactions to his show were ambivalent: some felt he went too far, they considered the show too controversial and not representative of the prevailing values of a society that, despite all its flamboyance, is conservative. ${ }^{9}$ Maxivive's approach already provides an idea of how fashion design is being used as a vehicle to spark conversations on social development, gender fluidity and androgyny. Oyeyemi thus stands for a new group of designers from Nigeria who question the conventions of men's fashion and create new freedom in fashion - and thus aim to renegotiate the meaning of masculinity completely.

Another artists who uses her work to address gender issues and challenge heteronormativity ${ }^{10}$ is Yagazie Emezi, a self-taught documentary photographer and cultural anthropologist from Aba, in southeast Nigeria. The fashion photography she made for the Vlisco brand, the famous but, because of its colonial past, controversial Dutch producer of wax prints, is particularly interesting in terms of a re-evaluation of long sidelined social practice in fashion and its media. Together with stylist and photographer Daniel Obasi, she set the stage for the fashion designs by Fruché and Gozel Green, a fashion line founded by the sisters Sylvia Enekwe and Olivia Enekwe-Okoji in 2012. ${ }^{11}$ Whereas the

From the blog Magnus Oculus by Mazzi Ozu, https://magnusoculus.com/tag/lagos-fash $t$ ion-week-ss-2019/ [7 November 2020].

10 Of course, there have been examples of fashion crossovers before - in street style as Misty Bastian (1996) showed for Onitsha in the 1980s or in high fashion. Shade Thomas-Fahm, for instance, adapted various elements of men's dress for women's fashion, most importantly the men's agbada. Thomas-Fahm, who was one of Nigeria's fashion pioneers of the 196 os constructed these garments through the careful interweaving of global and local styles. Her aim was to uphold Nigerian historical dress practices but at the same time update them. Cross-dressing then was mainly a way of protesting against gender stereotypes, as they were reinforced under British colonial rule and to challenge older forms of status and authority. Interview with Shade Thomas Fahm in Lagos, October 2017.

11 The twin sister's label is another example of a fashion design that stands against far reaching aesthetic premises of shininess and a desire for opulence and a heavy texture so prominent in mainstream design and a culture of ostentation and luxury. Their minimalist designs not only refer back to the 196os via cuts and materials; furthermore, they are inspired by the poems and writings of their late father, the well-known writer and poet 
collection's pieces - through asymmetric cuts, the mixing and interruption of patterns and textures in the case of Gozel Green, and with folding techniques and playing with volumes and an oversized silhouette with Fruché - already challenge conventional assumptions of gender conforming dressing - media images reinforce this direction even further. They stage the androgynous silhouettes and designs that blur female and male dress codes. Daniel Obasi, in particular, already had a reputation for work that critically engages with heteronormative expectations of how to dress, look and behave. ${ }^{12}$

For the Vlisco campaign, Yagazie Emezi mainly took up this theme by rediscovering and focusing on a cultural practice known among the Igbo of southeastern Nigeria but that for several reasons had disappeared. Against the setting of a concrete backyard veranda and its forged fence, her lens captured women holding hands and applying dark paint to each other's arms and hands. Present and Forgotten highlights two, once important but, in the course of colonization and Christianization, partly oppressed, partly discouraged cultural traditions. With the models adorned with calligraphy like patterns and signs in natural dyes, the images refer to the technique of uli: women's art of decorating their bodies and houses. Under British colonial rule uli was considered 'primitive', and patterns and colours were forced to move onto fabrics or, as in the case of the Zaria Rebels as an artists' association, onto canvas. In accordance with contemporary fashion photography, Emezi's images surpass the mere display of the garments, but instead focus on the relationship between the women.

Thus, the second element on which Yagazie Emezi focused with the models' body language stems from the Igbo custom of same-sex marriages as they existed in pre-colonial society. "The works created are an amalgamation of Igbo culture, present and forgotten," she writes on Instagram. "Before Christianity was introduced," the post continues, "women were permitted to choose a wife on the death of a husband where no child was born."13 In particular, in fashion design, the research into nearly forgotten or sidelined techniques of textile production or into the characteristics of materials has become a common practice among Nigerian fashion designers in the last ten years. Nothing less is done by Yagazie Emezi - the only difference being that she is concerned with local ways of knowledge, of 'traditional' epistemologies and cultural practices

Onuora Ossie Enekwe. For the Vlisco collection they used repetitive prints, which were cut out and appliquéd onto different fabrics next to other insignia and thus not only created a different kind of visuality, but also referred to the local women's technique of altering imported fabrics. The interview took place in their atelier in October 2018. https://www.yagazieemezi.com/present-and-forgotten [12 July 2021]. https://www.instagram.com/p/BsEL83VAZIo/ [7 November 2020]. 
associated with same-sex relations. Against the common image in the Western press, but also in the contemporary art discourse of presenting African societies as (per se) homophobic, Emezi's approach represents an important corrective and a complication of these stereotypical narratives. Fashion understood as an eminent part of contemporary culture sets out to spark debate; moreover, fashion designers are time unravellers who imagine possible futures.

\section{References}

Allman, J. (Ed.) 2004. Fashioning Africa: Power and the politics of dress. Bloomington: Indiana University Press.

Bastian, M. 1996. "Female 'alhajis' and entrepreneurial fashions: Flexible identities in southwestern Nigerian clothing practice." In Clothing and difference: Embodied Identities in colonial and post-colonial Africa, edited by H. Hendrickson, 97-132. Durham, NC: Duke University Press.

Breward, C. and D. Gilbert (Eds). 2006. Fashion's world cities. Oxford: Berg.

Eicher, J. B. (Ed.). 1995. Dress and ethnicity. Change across space and time. Oxford: Berg. Eicher, J. B. and D. Ross (Eds). 2010. Berg encyclopedia of world dress and fashion. Volume 1: Africa. Oxford: Berg Publishers.

Geczy A. and V. Karaminas (Eds). 2017. Critical fashion practice. From Westwood to Van Beirendonck. London: Bloomsbury.

Kastner, K. 2019. "Fashioning Dakar's urban society: Sartorial code-mixing in Senegal." Sociologus, 69, 2: 167-188.

Lokko, L. 2018. "In the skin of a lion, a leopard ... a man." In Superhumanity: Design of the self, edited by N. Axel, B. Colomina, N. Hirsch, A. Vidokle and M. Wigley, 127-134. Minneapolis: University of Minnesota Press.

Miller, D. 1994. "Style and ontology." In Consumption and Identity, edited by J. Friedmann, 71-96. Chur: Harwood Academic Publishers.

Mustafa, H. N. 1998. "Sartorial ecumenes: African styles in a social and economic context." In The art of African fashion, edited by E. van der Plas and M. Willemsen (Prince Claus Fund), 13-48. Trenton, NJ: Africa Word Press.

Oberhofer, M. A. 2012. "Fashioning African cities: The case of Johannesburg, Lagos and Douala." Streetnotes, 20, 1: 65-89. https://escholarship.org/uc/item/4dv2g2n9

Omi - Water. 1974. [Short film] O. Sembène. dir., Maki Oh (fashion label). Nigeria: Whitespace Creative Agency.

Okeowo, A., 2017. "West Africa most daring designer." The New Yorker, 18 September. https://www.newyorker.com/magazine/2017/og/25/the-daring-designs-of-amakaosakwe [7 November 2020]. 
Pinther, K. 2013. "Negotiating signs of Africa in the fashion design of Xuly Bët and Buki Akib." In Anziehen! Transkulturelle Moden (Zeitschrift für Zeitgenössisches, Kunst, Populärkultur, Heft 6), edited by B. Haehnel, A. Karentzos, J. Petri and N. Trauth, 28-40. Bielefeld: Transcript.

Pinther, K., K. Kastner and B. Ndjio (Eds). 2022. Fashioning the Afropolis: Histories, materialities and aesthetic practices. London: Bloomsbury.

Potvin, J. (Ed.). 2009. The places and spaces offashion, 1800-2007. New York: Routledge.

Richards, C. 2016. "'The models for Africa.' Accra's independence-era fashion culture and the creations of Chez Julie." African Arts, 49, 3: 8-21.

Rovine, V. 2015. African fashion, global styles. Histories, innovations, and ideas you can wear. Bloomington: Indiana University Press.

Tulloch, C. 2016. Birth of the cool: Style narratives of the African diaspora. London: Bloomsbury.

Vinken, B. 2019. Fashion: An oriental tyranny in the heart of the West. In Fashion and politics, edited by D. Bartlett, 61-71. New Heaven: Yale University Press.

Xala. 1974. [Film] O. Sembène. dir., Senegal: New Yorker Films. 